\title{
Tumor mimicking bladder endometriosis
}

\author{
Ulku Kucuk ${ }^{1}$, Emel Ebru Pala ${ }^{1}$, Halil Gursoy Pala ${ }^{2}$, Ebru Cakir $^{1}$, Rauf Taner Divrik $^{3}$
}

\begin{abstract}
Endometriosis is described as the presence of endometrial tissue outside the uterine corpus. Though urinary tract endometriosis is uncommon, the bladder is the most common localization amongst them. Here we present three cases admitted to our hospital with similar complaints such as dysuria and abdominal pain. All of the patients had previous cesarean section history. And radiological examination of the bladder revealed solid masses located on the bladder wall. One of the cases additionally had a protruding, polipoid luminal mass. Two of the cases were treated with transurethral resection and one with partial cystectomy. We noted similar histological findings such as endometrial stroma and glands within the smooth muscle fibers. The stromal components were positive with CD10, epithelial components were positive with both estrogen and progesterone receptor immunohistochemically. As a result bladder endometriosis should be kept in mind in the differential diagnosis of mass forming urinary tract lesions.
\end{abstract}

Key Words: Endometriosis, Urinary System, Bladder, Treatment

\section{Introduction}

Endometriosis is the most common gynecologic disorder amongst women [1]. It is defined as the presence of endometrial tissue (glands and/or stroma) outside the uterine corpus [2]. Approximately $1 \%$ of women with pelvic endometriosis have urinary tract endometriosis (UTE) [3]. In urinary tract, the disease is mostly seen in bladder (80-84), ureter (15\%), kidney $(4 \%)$, urethra $(2 \%)$ [4]. Here we present three urinary bladder endometriosis cases in terms of clinical, radiological and morphological features.

Case-1: 41-years old woman was admitted to our hospital with weight loss, grumble, dysuria and hematuria. She had a previous cesarean section history. Abdominal ultrasonography (USG) revealed $3.6 \times 2.4 \mathrm{~cm}$ mass at the posterior wall of the urinary bladder. On computed tomography (CT) $8 \times 5 \mathrm{~cm}$ sized, solid hyperdense mass was noticed at the superior midline of the bladder. The mass had lobulated, well-circumscribed contours and homogenous texture with no distinct peripheral invasion (Figure 1A). Hemorrhagic curetted material (3 cc) was obtained by transurethral resection of bladder (TURB).

Case-2: 43-years old woman was admitted to our hospital with long-term dysuria and abdominal pain. She also had cesarean section history. Pelvic magnetic resonance imaging (MRI) revealed a protruding mass $(3,5 \mathrm{~cm})$ at the left side of the posterior wall. The lobular solid mass had same intensity with myometrium (Figure 1B). Hemorrhagic curetted material (6 cc) was obtained by TUR-B.

Case-3: 31-years old woman with three months old new pregnancy complained of dysuria and pelvic pain. She also had previous cesarean section in history. Pelvic USG of the case revealed $3.8 \times 3.3 \times$ $2.5 \mathrm{~cm}$ sized hyperchogenic lobular solid mass with irregular borders. The case following in obstetric clinic was consulted to urology clinic. On MRI, 3.5 $\mathrm{cm}$ sized solid mass was observed at the superior wall of the bladder. TUR-B was planned after delivery. During cesarean section urologist consulted the case again and decided partial cystectomy. The operation specimen was $4.5 \mathrm{x} 4 \mathrm{x}$ $3.5 \mathrm{~cm}$ sized nodular mass. One side of the lesion was papillary and the other side was solid. The cut surface was gray-white and partially hemorrhagic.

All three cases had similar histological findings with endometrial stroma and glandular structures within the smooth muscle fibers. Case 3 showed decidualization in the endometrial stroma due to the pregnancy (Figure 2A, Figure 2B). The stromal components were positive with CD10, epithelial components were positive with both estrogen and progesterone receptor immunohistochemically (Figure 2C, Figure 2D).

Received 08-01-2015 Accepted 10-01-2015 Available Online 10-01-2015

${ }^{1}$ Izmir Tepecik Research and Training Hospital, Department of Pathology, TURKEY

${ }^{2}$ Celal Bayar University School of Medicine, Department of Obstetrics and Gynecology, TURKEY

${ }^{3}$ Izmir Tepecik Research and Training Hospital, Department of Urology, TURKEY

*Corresponding Author: Ulku Kucuk E-mail: kucukulku@hotmail.com 


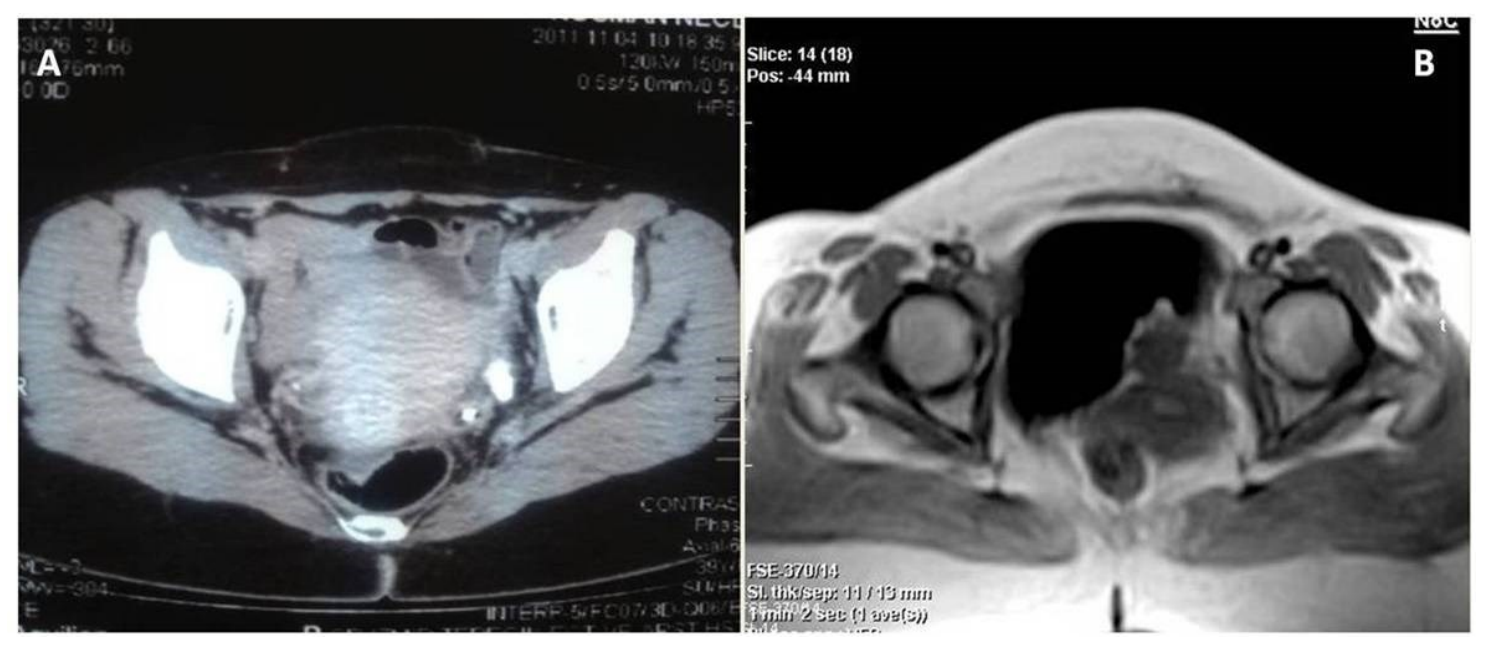

Figure 1: (A) Solid hyperdens mass with minimally lobulated contours and homogenous texture in the midline superior of the bladder on CT. (B) The mass protruding into the lumen in the left side posterior of the bladder on pelvic MRI.
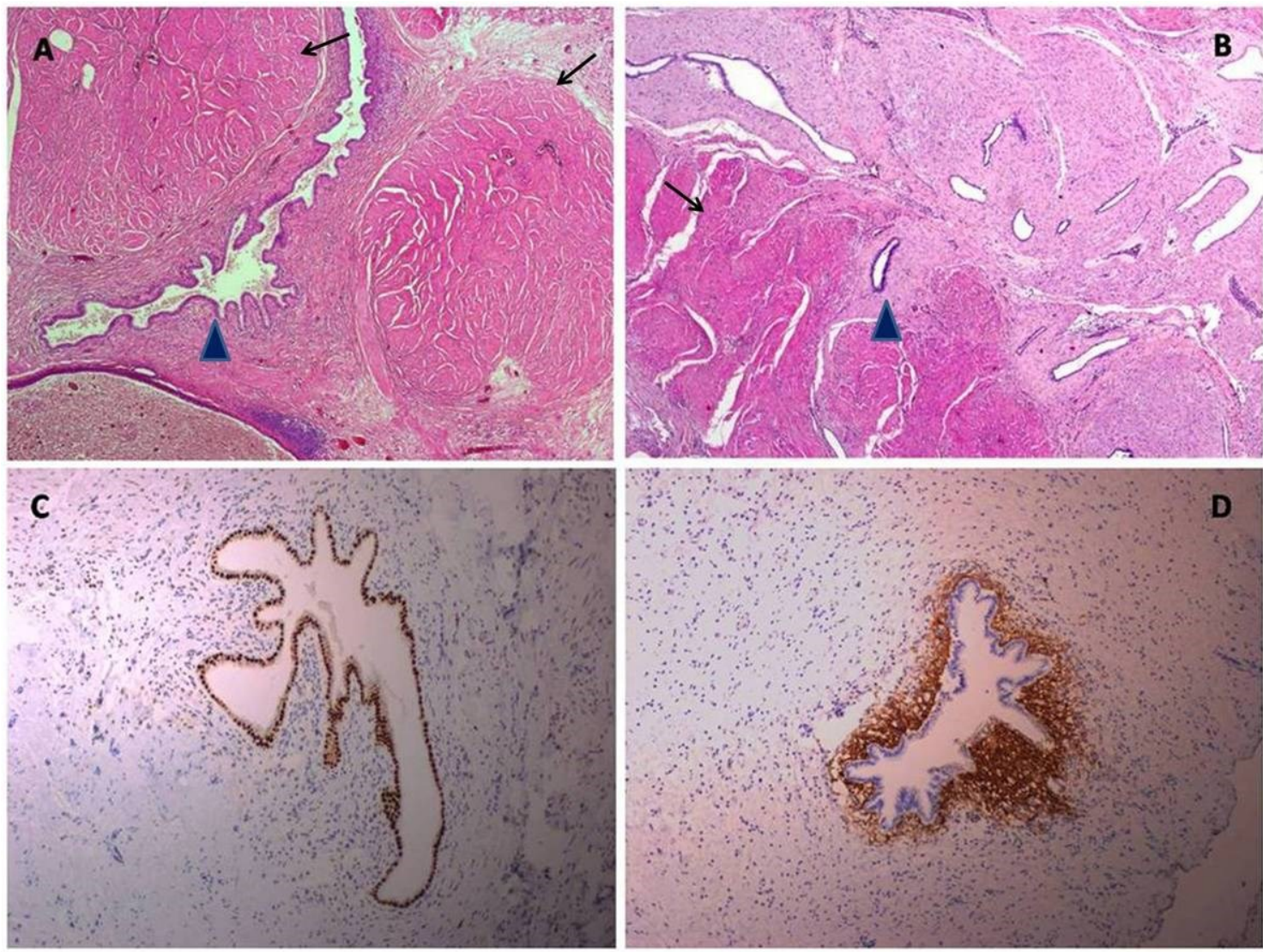

Figure 2: (A) Endometrial stroma and gland structures amongst the smooth muscle fibers (HEX40). (B) Desidualization of the endometrial stroma and gland structures amongst the smooth muscle fibers in the pregnant case (HEX40). (C) Epithelial components positive with progesterone receptor DAPX100, (D) Stromal components positive with CD10 immunohistochemically (DABX100). ( $\Delta$ : endometrial stroma and gland structures, $\rightarrow$ : smooth muscle fibers) 
Discussion

Pelvic endometriosis is mostly detected in ovary (54\%), broad ligament (35\%), Douglas sac $(35 \%)$ and uterosacral ligament $(8 \%)$ respectively [2]. Approximately $1 \%$ of the women with pelvic endometriosis presents with UTE [2]. Endometriosis is most common in 2-5th decades but postmenopausal women who had exogenous estrogen therapy can be affected [5].

In English literature, more than 300 reports have been published about urinary bladder endometriosis. The most common involvement sites are urinary bladder $(80-84 \%)$, ureter $(15 \%)$, kidney $(4 \%)$, urethra (2\%) respectively [4].

Endometriosis is a chronic, multifactorial systemic disease [6]. Etiopathogenesis is not known exactly. There are many different theories in the etiopathogenesis of urinary tract endometriosis. The most widely accepted theory is implantation of endometrial tissue after menstrual reflux. The discussion point is that although nearly all women have retrograd menstruation, the prevalence of urinary tract endometriosis is rare. So additional factors such as genetic, environmental, endocrinological, immunological might also play a role in the pathogenesis [6].

Embryogenic theory suggests that endometriosis develops from the metaplasia of Wolfian, Mullerian and peritoneal structures. Immunological theory suggests that there is an incomplete immunological response to prevent ectopic implantation of endometrial tissue [7].

Cesarean section is a risk factor for endometrioma at the operation site. Andolf et al found a relationship between $\mathrm{C} / \mathrm{S}$ and pelvic endometriosis [8]. But the relation between $\mathrm{C} / \mathrm{S}$ and endometriosis should be analyzed with different comprehensive studies. All of our cases also had previous $\mathrm{C} / \mathrm{S}$ in history.

Patients with UTE have no specific clinical symptoms. Nearly half of the cases are asymptomatic [9]. Urgency, suprapubic pain and hematuria are the most common complaints [5]. Our cases had dysuria, abdominal pain, hematuria, weight loss and grumble.

Urinary tract endometriosis may be detected with palpation or by endoscopic examination [5]. It may be seen within the wall of urinary bladder, deeply or superficially and perivesical soft tissue. So the diagnosis can be missed by TURB.

Clinical and laparoscopic findings are not always diagnostic because of nonspecific endoscopic findings [3]. Imaging techniques can be useful to determine diagnosis. The initial radiologic technique should be USG which aids distinction of solid and cystic components. But endometriosis may have many different radiologic findings and none of them is specific. The most specific technique seems MRI, since the depth and the size of the lesion can be determined clearly [2].
The disease is locally aggressive with low recurrence risk. Definitive treatment is surgery and hormonotherapy [10]. Two of our cases were treated with TUR-B and one case was treated with partial cystectomy. As the symptoms restored, the cases were started to follow up yearly with urine cytology. The control cystoscopy of the patient treated with partial cystectomy was normal. Patient 2 was out of follow up during five years but the bladder mucosa was observed normally at a recent cytoscopic examination. All of the cases are still following with routine urine cytology without any symptoms.

The bladder is an uncommon localization for endometriosis. It may mimic bladder tumors both clinically and radiologically. Endometriosis should be kept in mind in the differential diagnosis of tumoral lesions of the urinary tract in women.

Conflict of Interest: The authors declare no potential conflicts of interest with respect to the research, authorship, and/or publication of this article.

\section{References}

1. Bologna RA, Whitmore KE. Genitourinary endometriosis. AUA Update Series. 2001;1:21

2. Perez-Utrilla Perez M, Aguilera Bazan A, Alonso Dorrego JM, Hernandez A, de Francisco MG, Martin Hernandez $M$, et al. Urinary tract endometriosis: clinical, diagnostic, and therapeutic aspects. Urology. 2009;73(1):47-51.

3. Gabriel B, Nassif J, Trompoukis P, Barata S, Wattiez A. Prevalence and management of urinary tract endometriosis: a clinical case series. Urology. 2011;78(6):1269-74

4. Donnez J, Spada F, Squifflet J, Nisolle M. Bladder endometriosis must be considered as bladder adenomyosis. Fertility and sterility. 2000;74(6):117581.

5. Epstein JI, Reuter VE, Amin MB. Biopsy Interpretation of Bladder. 2nd ed. Philedelphia, Lippincott Williams \&Wilkins. 2010;180-213.

6. Siva AB, Srivastava P, Shivaji S. Understanding the pathogenesis of endometriosis through proteomics: recent advances and future prospects. Proteomics Clinical applications. 2014;8(1-2):86-98

7. Al-Khawaja M, Tan PH, MacLennan GT, LopezBeltran A, Montironi R, Cheng L. Ureteral endometriosis: clinicopathological and immunohistochemical study of 7 cases. Human pathology. 2008;39(6):954-9.

8. Andolf E, Thorsell M, Kallen K. Caesarean section and risk for endometriosis: a prospective cohort study of Swedish registries. BJOG : an international journal of obstetrics and gynaecology. 2013;120(9):1061-5. 
9. Seracchioli R, Mabrouk M, Montanari G, Manuzzi L, Concetti S, Venturoli S. Conservative laparoscopic management of urinary tract endometriosis (UTE): surgical outcome and long-term follow-up. Fertility and sterility. 2010;94(3):856-61.
10. Antonelli A, Simeone C, Zani D, Sacconi T, Minini G, Canossi E, et al. Clinical aspects and surgical treatment of urinary tract endometriosis: our experience with 31 cases. European urology. 2006;49(6):1093-7; discussion $7-8$

Copyright (C) 2014 The Author(s); This is an open-access article distributed under the terms of the Creative Commons Attribution License (http://creativecommons.org/licenses/by/4.0), which permits unrestricted use, distribution, and reproduction in any medium, provided the original work is properly cited. 